\title{
Study on the Relationship between Residents' Income and Subjective Well-being (SWB) in Chinese Context
}

\author{
Qiance Qiu \\ University of California Irvine, Irvine, 92697, USA
}

\begin{abstract}
In recent years, the economic research on SWB has developed rapidly. A large number of academic achievements have emerged to explore the influencing factors of SWB. In view of this, this study has collated and reviewed the domestic and foreign literature on the relationship between income and SWB, and then summarized and commented on the impact of absolute income, relative income and income gap on SWB. The research results show that: in the context of China, absolute income and relative income have a positive impact on residents' Well-being in general, and income gap reduces residents' Well-being; Compared with absolute income, relative income exerts a greater impact on SWB; Compared with high-income groups, absolute income and relative income demonstrate a greater influence on the SWB of low-income groups. On this basis, this study has put forward specific policy proposals.
\end{abstract}

Keywords: Subjective Well-being (SWB); Absolute Income; Relative Income; Income Gap; Literature Review.

\section{Introduction}

Happiness is defined as utility in economics and subjective Well-being (SWB) in psychology (Tian \& Yang, 2006). SWB is an individual's overall assessment of their quality of life according to their own standards, which mainly consists of satisfaction with life, experience of positive emotions and lack of negative emotions (Ren, Gui \& Liu, 2012). In 1974, Easterlin creatively introduced the psychological research of SWB into the field of economics, which attracted a wide range of scholars' interest. The research on SWB in economics showed an exponential growth in both scale and depth (Kahneman \& Krueger, 2006).

The factors affecting SWB can be generalized as the following happiness function: $\mathrm{H}=\mathrm{f}(\mathrm{P}, \mathrm{E}$, I, ...) (Lu \& Wang, 2010). In this formula, the explained variable $\mathrm{H}$ represents happiness (SWB), and the explanatory variable $\mathrm{P}$ stands for demographic sociological factors, including age, gender, race, health, marriage, educational level, religious beliefs, etc.; E for the economic factors, including absolute income, relative income, income inequality, unemployment, inflation, government expenditure, environmental pollution and urbanization, etc.; and I for social system conditions, such as direct democratic rights, degree of local autonomy, etc.

However, the empirical research on the survey data of SWB shows that the average Well-being of the people does not increase as a country becomes richer. This phenomenon is called "Easterlin Paradox" (Easterlin, 1974) which has appeared in many developed countries such as the United States, Britain, Japan, etc. (Oswald, 1997), and is now can be used to describe China's current condition. Previous studies have shown that Chinese people's happiness has increased first and then decreased in the past 10 years, which is not in line with the curve of economic development (Dai, 2006). In order to give a reasonable explanation to Easterlin Paradox, the possible perspectives in existing researches are as follows. One is from the aspects of psychological satisfaction, family life quality, health level, basic human rights, unemployment and inflation (Graham \& Pettinato, 2002), to explore its impact on individual happiness level; Another one is to further explore the most important factor affecting SWB---income.

On the impact of income on SWB, scholars initially explained the Well-being with absolute income, and then examined the relative income, and the income gap (income inequality) has become a recent research hotspot (Yang \& Zhang, 2016). However, there are still some deficiencies in the summary results in this field. First, the foreign research on income and SWB started in 1974 (Easterlin, 1974), while the domestic research started around 2004 (Zhao, 2004), and the related summary results 
were produced after 2010 (Ren, Gui \& Liu, 2012). In recent years, the research focusing on income gap and income inequality has not been systematically explored.

In addition, although most scholars believe that income can promote SWB, due to the research situation, sample characteristics and other factors, researchers found that income and SWB can show positive correlation, negative correlation, inverted U-shaped correlation and even no significant correlation (Ma \& Xi, 2020). The differences in research conclusions have affected scholars' in-depth analysis of this issue to a certain extent. Therefore, the analysis and integration of the different research results in the context of China, and the induction and review of the impact on SWB from three aspects of absolute income, relative income and income gap, are helpful to better clarify the underlying logical relationship between income and SWB, and then put forward targeted policy recommendations.

\section{Absolute Income and Subjective Well-being}

There is a positive correlation between SWB and income. For example, the research on developed countries (Frey \& Stutzer, 2002) and the research on developing countries (Graham \& Pettinato, 2002) all found that the rich have higher SWB than the poor. Moreover, the income effect of developing countries is greater than that of developed countries (Clark et al., 2005). That is, in the normal sense, the higher the absolute income, the higher the SWB.

After using panel data to eliminate the possible deviation of unobservable fixed effects such as individual characteristics, it is found that the marginal Well-being brought by absolute income decreases with the increase of income, but the relationship between income and happiness is still significantly positive (Ferrer-i-Carbonell, 2005). You, Yang \& Huo (2019) found that absolute income has a significant improvement on farmers' SWB, but there is a "Matthew effect": income desire has a significant negative effect on farmers' SWB, and income desire plays a moderated role in the impact of absolute income on farmers' SWB. That is, with the increase of income desire, the improvement of absolute income on farmers' SWB is becoming smaller and smaller.

In addition, absolute income can improve the SWB of low-income groups, while it creates little impact on the improvement of high-income groups. Wu \& Zhou (2017) found that absolute income and relative income are positive to SWB. For low-income groups, absolute income has a significant positive impact on SWB but relative income does not. i.e., the increase in absolute income of lowincome earners can improve their satisfaction with family relationships, interpersonal relationships and their own health status. Liu C.K. \& Liu C. (2018) found that absolute income has a significant positive impact on the SWB of each income group after controlling other variables besides income factors, but the impact degree is different, and it has the greatest impact on low-income groups. The $\mathrm{SWB}$ of the middle-and-low-income groups is most obviously affected by the expected income. $\mathrm{Xu}$, Zhang \& Fu (2020) found that increasing absolute income can significantly improve the Well-being of rural residents. Moreover, the promotion of absolute income on the Well-being of rural residents is more obvious in the groups of farmers aged 30-60, low income and low market competition.

\section{Relative Income and Subjective Well-being}

Besides absolute income, relative income is also considered as an important factor affecting SWB, which is used to explain why economic growth does not bring more happiness at the social level (Luo, 2009). Relative income theory holds that people are always used to comparing with others, and the comparing mentality between people will reduce happiness. When all people's income rises in the same proportion, people's SWB will not change much (Ferrer-i-Carbonell, 2005). Easterlin is a representative who emphasizes that relative income plays a decisive role in SWB. He emphasizes in a series of articles that SWB depends on relative income rather than absolute income. At least, relative income has a more important impact on SWB. SWB changes positively with the increase of one's own income level, but changes reversely with the increase of others' income level (Easterlin, 1995). 
In the study of the relationship between SWB and relative income, it is generally assumed that there is a certain control group, and there is a negative correlation between individual SWB evaluation and the income level of the control group. Ferrer-i-Carpinell (2005) believes that, relative to other objective variables, income plays a very important role in the decision of SWB; The higher the relative income, the stronger the SWB, but this effect is different in different income groups. For the people whose income is lower than that of the control group, the difference between their own income and that of the control group has a serious negative effect on their SWB; For the people with higher income than the control group, the positive effect of relative income on SWB is relatively low.

Luttmer (2005) found that there is only a very weak correlation between SWB of self-evaluation and absolute income level, but there is a significant negative correlation with relative income, and the impact of relative income on SWB is far greater than absolute income. Similar results can be found in studies conducted by Chinese scholars: Guan (2010) found that absolute income does not have a significant impact on happiness after considering the relative measure of income, while relative income has a significant positive impact on happiness, that is, the higher relative income, the stronger happiness. Ren \& Fu (2011) found that absolute income has a great influence on happiness, regardless of whether relative income is considered or not. When relative income is considered, the influence of absolute income is weakened; In comparison, relative income measured by average income has a stronger effect on happiness than absolute income. In conclusion, relative income has a greater impact on SWB than absolute income.

The impact of relative income on SWB in the context of China is different from other Asian countries. OSHIO et al. (2014) conducted a nationwide large-scale survey in China, Japan and South Korea to analyze the impact of relative income on SWB. The study found that in the context of China, the correlation between individual's relative income and Well-being is greater than the correlation between family's relative income and Well-being, while the situation in Japan and South Korea is the opposite. Domestic researchers have carried out an in-depth discussion in the context in China: Liu, C. K. \& Liu, C. (2018) based on the data from the 2015 China Comprehensive Social Survey, using the method of ordered probability regression analysis, found that it is more accurate to measure the happiness level of high-income groups by subjective relative income grouping. $\mathrm{Hu}, \mathrm{Wu} \& \mathrm{Wang}$ (2015) found that both relative income and income satisfaction have significant promotion effect on SWB, and income satisfaction has significant mediating effect on relative income and SWB. Pei (2010) analyzed the relationship between life satisfaction and emotional experience of rural residents' relative income and SWB, concluded that relative income has a significant impact on life satisfaction, but the impact on emotional experience is not significant, and proposed that in order to improve rural residents' SWB, rural residents' income should be increased and the income gap should be narrowed.

\section{Income Gap and Subjective Well-being}

Different from relative income, income gap examines the impact of a country's or region's income distribution system or status quo on residents' happiness. On the impact of income gap on SWB, scholars have not yet reached a consistent conclusion, there are the following two major mainstream views:

One is the "expectations changing theory", that is, the income gap can change the income expectations and thus affect people's SWB (He \& Pan, 2011). Rational individuals regard the inequality of current income as an agent variable to depict the uncertainty of future income. Under the assumption of risk avoidance, the expansion of the current social income gap enhances the uncertainty of expected income, thus reducing the level of individual utility or happiness (Harsanyi, 1955).

The second is "relative deprivation theory", that is, the income gap can produce relative deprivation and affect people's SWB. Relative deprivation refers to a kind of negative psychological experience when people find themselves at a disadvantage by comparing with the reference group, which results in negative feelings (Hey \& Lambert, 1980). At present, some scholars have quantitatively analyzed 
the relationship between relative deprivation and individual SWB from the aspects of individual economy such as income, welfare, material wealth and social status. For example, Zhang et al. (2010) respectively analyzed the relationship between relative deprivation of individual economy and relative deprivation of social status, and life dissatisfaction. The results showed that with the increase of relative deprivation of economy, the degree of individual dissatisfaction with life will also increase, and the relative deprivation of social status of individual self-assessment will also positively promote life dissatisfaction.

In the context of China, Yu and Wang (2020) used the Chinese Social Survey Database to analyze the impact of income inequality on farmers' life satisfaction through Ordered Probit and two-stage Probit least squares simultaneous equation model, and concluded that income inequality significantly reduces farmers' life satisfaction and the inhibitory effect exists regional and group heterogeneity. Xue (2019) classified the income gap into reasonable, unreasonable and neutral income gap from the perspective of value judgment, and pointed out that reasonable income gap should be encouraged, unreasonable income gap should be contained, and neutral income gap should be controlled within a tolerable range, so as to improve residents' happiness. Xu and Chen (2017) used data from China Labor-force Dynamics Survey to conduct an empirical study, suggesting that the effect of fair perception on happiness is greater than that of income and social status. The results of Shen and Jia (2016) show that the increase of income gap will lead to the decrease of residents' Well-being, which is mainly affected by the uneven allocation of education and medical resources. Ren and $\mathrm{Fu}(2012)$ empirically investigated the impact of Gini coefficient on the Well-being of Chinese residents by using the correlation coefficient method and the method of ordered probability regression, that is, the income gap has a significant negative impact on the Well-being of urban residents, while the negative impact on the Well-being of rural residents is not statistically significant. In addition, the impact of income gap on SWB varies among different countries (Bjornskov, 2003), which may depend on the impact of social culture on residents' understanding. In the context of China, the residents have the thought of "what matters is not wanting but unfairness" and are very disgusted with the phenomenon of income inequality. Then the income gap will definitely have a negative impact on the SWB.

\section{Research Conclusions and Implications}

This study has collated and reviewed the domestic and foreign literature on the relationship between income and SWB, and then has further summarized and commented on the impact of absolute income, relative income and income gap on SWB. In the context of China, absolute income and relative income have a negative impact on residents' Well-being. Compared with absolute income, relative income has a greater impact on SWB. Compared with the high-income groups, absolute income and relative income have a greater impact on the SWB of the low-income groups, and the effect of improvement is greater.

On the basis of the research conclusions, this study puts forward the following policy recommendations:

\subsection{GDP should not be the Only Criterion for Social Success}

The "Easterlin Paradox " indicates that the increase of absolute income of all people is not a sufficient condition to increase happiness, and there is no obvious connection between economic growth and national happiness. In this case, the previous "GDP-only" economic development strategy is obviously inappropriate (Zhang \& Cai, 2011). Huang (2003) pointed out that if the impact of environmental damage is considered, economic growth may lead to a decline in human happiness. Since the 12th Five-Year Plan, although governments at all levels have made "improving residents' happiness index, taking the road of people's livelihood-oriented development, and allowing the people to share more development achievements" as their development priorities, they have further drawn on existing research results, and compared Gross National Happiness, Happy Planet Index, 
Environmental Responsibility Happy Nation Index, and other happiness indicators included in the government performance appraisal (Lu \& Wang, 2010), which are of great practical significance.

\subsection{Public Policies should Pay More Attention to Fairness}

Most happiness economists emphasize the influence of relative income on individual SWB. Because once the individual's income exceeds the normal level of subsistence, happiness depends more on relative income than absolute income and other non-economic factors. However, happiness economics believes that this kind of relative positions competition is a kind of social waste, which will lead to a decline in the overall happiness of the society. Previous studies have shown that the magnitude of impact on national happiness is income inequality, relative income and absolute income in turn. Chinese people are more affected by "what matters is not wanting but unfairness" (Yang \& Zhang, 2016). Therefore, the government should actively pay attention to income fairness, and reasonably adjust the gap between the rich and the poor by levying property tax, increasing the exemption of individual income tax and the range and proportion of individual income tax. The government's public policy should shift from the pursuit of economic growth to the pursuit of establishing and maintaining a healthy, fair and just macro-institutional arrangement, so as to reduce social pressure brought by the social gap between the rich and the poor, such as "hatred for the rich", and realize social harmony and stability and the happiness of the residents.

\section{References}

[1] Bjørnskov, C. (2003). The happy few: Cross-country evidence on social capital and life satisfaction. Kyklos, 56(1), 3-16.

[2] Dai Lian. (2006). Happiness index quantifies harmonious society. Outlook Newsweek (11), 24-26.

[3] Easterlin, R. A. (1974). Does economic growth improve the human lot? Some empirical evidence. In Nations and households in economic growth (pp. 89-125). Academic Press.

[4] Easterlin, R. A. (1995). Will raising the incomes of all increase the happiness of all?. Journal of Economic Behavior \& Organization, 27(1), 35-47.

[5] Ferrer-i-Carbonell, A. (2005). Income and Well-being: An empirical analysis of the comparison income effect. Journal of Public Economics, 89(5-6), 997-1019.

[6] Frey, B. S., \& Stutzer, A. (2002). What can economists learn from happiness research?. Journal of Economic Literature, 40(2), 402-435.

[7] Graham, C., \& Pettinato, S. (2002). Frustrated achievers: Winners, losers and subjective Well-being in new market economies. Journal of Development Studies, 38(4), 100-140.

[8] Guan, H. (2010). Research on the impact of income on Well-being: Absolute level and relative position. Nankai Economic Research (05), 56-70.

[9] Harsanyi, J. C. (1955). Cardinal welfare, individualistic ethics, and interpersonal comparisons of utility. Journal of Political Economy, 63(4), 309-321.

[10] He L., \& Pan, C. (2011). Decoding China's "Easterlin Paradox": Income Gap, unequal opportunities and residents' happiness. Journal of Management World (08), 11-22+187.

[11] Hey, J. D., \& Lambert, P. J. (1980). Relative deprivation and the Gini coefficient: comment. The Quarterly Journal of Economics, 95(3), 567-573.

[12] Hu, C., Wu, J., \& Wang, Y. (2015). Relative income, income satisfaction and subjective Well-being. Journal of Xi'an Jiaotong University (Social Sciences Edition) (03).

[13] Huang, Y. (2003). Talk about utility, welfare and happiness-Some Thoughts on "Three People Talk Record". Zhejiang Social Sciences (02).

[14] Kahneman, D., \& Krueger, A. B. (2006). Developments in the measurement of subjective Well-being. Journal of Economic Perspectives, 20(1), 3-24.

[15] Liu, C., \& Liu, C. (2018). Relative income, expected income and subjective Well-being. Journal of Central South University for Nationalities (Humanities and Social Sciences Edition) (06), 139-142. 
[16] Lu, Y., \& Wang, T. (2010). Review on the research of influencing factors of subjective Well-being. Economic Trends (05), 125-130.

[17] Luo, C. (2009). Absolute income, relative income and subjective Well-being: An empirical analysis from China's urban and rural household survey data. Financial Research (11), 79-91.

[18] Luttmer, E. F. (2005). Neighbors as negatives: relative earnings and Well-being. the Quarterly Journal of Economics, 120(3), 963-1002.

[19] Ma, H., \& Xi, H. (2020). Income gap, social security and promoting residents' sense of Well-being and access. Social Security Research (01), 86-98.

[20] Oswald, A. J. (1997). Happiness and economic performance. the Economic Journal, 107(445), 1815-1831.

[21] Pei, Z. (2010). Family social capital, relative income and subjective Well-being: an empirical study of a rural area in western Zhejiang. Agricultural Economic Issues (07), 22-29+111.

[22] Ren, G., Gui, Y., \& Liu, G. (2012). Impact of income on subjective Well-being--International experience and domestic evidence. Exploring Economic Issues (07), 23-32.

[23] Ren, H., \& Fu, H. (2011). Verification of the relationship between income and residents' Well-being in China-- Based on the analysis of absolute income and relative income. Nanjing Social Sciences (12), 1521.

[24] Ren, H., \& Fu, H. (2012). Research on income gap and Well-being of Chinese residents based on ordered probability model. Search (03), 1-4.

[25] Shen, Y., \& Jia, J. (2016). Empirical research on income gap, social capital and Well-being. Journal of Public Management (03), 100-110+158.

[26] Takashi, K., Huasi, N., Miki, K., et al. (2014). Relative income and happiness in Asia: Evidence from national surveys in China, Japan and South Korea. Foreign Theoretical Trends (06), 65-74.

[27] Tian, G., \& Yang, L. (2006). An answer to the "Happiness-Income Mystery". Economic Research (11), 4 $-15$.

[28] Wu, Q., \& Zhou, B. (2017). Absolute income, relative income and Easterlin Paradox: an empirical study based on CGSS. Nankai Economic Research (04), 41-58.

[29] Xu, H., Zhang, Y., \& Fu, G. (2020). Absolute income, social stratum identification and rural residents' Well-being: Micro-empirical evidence based on CGSS. Agricultural Technology Economy (11), 56-71.

[30] Xu, S., \& Chen, P. (2017). Income, social status and happiness-- From the perspective of fairness perception. Journal of Management Science (12), 99-116.

[31] Xue, B. (2019). Three types of income gap: A perspective of value judgment. Social Sciences in Ningxia (02), 78-83.

[32] Yang, Y., \& Zhang, S. (2016). Income inequality, social security and the happiness of China. Financial Research (08), 34-50.

[33] You, L., Yang, J., \& Huo, X. (2019). Absolute income, income desire and farmers' subjective Well-being: An empirical study based on two whole-village farmers in Shaanxi Province. Journal of Shanxi University of Finance and Economics (03), 16-30.

[34] Yu, J., \& Wang, J. (2020). Income inequality and farmers' life satisfaction-- From the Comprehensive Survey of Chinese Society. Agricultural Economy and Management (05), 78-89.

[35] Zhang, S., Wang, E., \& Chen, Y. (2011). Relative deprivation based on occupation: An effective predictor of Chinese life satisfaction. Asian Journal of Social Psychology, 14(2), 148-158.

[36] Zhang, X., \& Cai, G. (2011). Income, values and residents' Well-being: Empirical evidence from Guangdong Adult Survey Data. Journal of Management World (09), 63-73.

[37] Zhao, F. (2004). An economic study of the relationship between income and happiness. Financial Research (05). 